Original Research Paper

\title{
Penggunaan KIT IPA Sederhana sebagai Media Pembelajaran Efektif pada Siswa di YPI Bidayatul Hidayah Ampenan
}

\author{
Fuad Tamami' ${ }^{1}$, Rabiatul Adawiyah ${ }^{1}$, Siswadi $^{1}$ \\ ${ }^{I}$ Magister Pendidikan IPA, Universitas Mataram, Mataram, Indonesia;
}

https://doi.org/10.29303/jpmpi.v3i2.665

Sitasi: Tamami, F., Adawiyah, R., \& Siswadi. (2021). Penggunaan KIT IPA Sederhana sebagai Media Pembelajaran Efektif pada Siswa di YPI Bidayatul Hidayah Ampenan. Jurnal Pengabdian Magister Pendidikan IPA, 4(1)

\section{Article history}

Received: 03 Februari 2021

Revised: 08 Maret 2021

Accepted: 06 April 2021

*Corresponding Author: Fuad Tamami, Magister Pendidikan IPA Universitas Mataram,

Mataram, Indonesia;

Email:

fuadtamami@unram.ac.id

\begin{abstract}
Kegiatan ini bertujuan untuk memberikan penyuluhan untuk penggunaan KIT IPA sederhana untuk pembelajaran efektif pada siswa di YPI Biyadatul Hidayah Ampenan. Keterbatasan alat praktikum menjadi salah satu kendala yang dihadapi guru dalam melaksanakan pembelajaran IPA secara menarik. Media pembelajaran IPA tidak hanya menggunakan alat yang mahal, namun juga dapat dibuat dengan bahan-bahan yang dapat ditemukan di lingkungan sekitar. Metode yang digunakan pada kegiatan ini adalah dengan mentransfer pengetahuan dari tim pengabdian kepada para guru IPA SMP di YBI Biyadatul Hidayah Ampenan. Adapun pokok-pokok materi yang disampaikan meliputi, (1) penyampaian topik IPA yang penting untuk menggunakan media dalam penyampaiannya, (2) pemaparan cara membuat KIT IPA sederhana terkait topik IPA yang disampaikan, serta (3) demonstrasi penggunaaan KIT IPA sederhana. Sasaran kegiatan pengabdian ini adalah 17 guru IPA yang ada di YPI Biyadatul Hidayah Ampenan. Kegiatan penyuluhan diwarnai dengan antusiasme peserta yang tinggi.
\end{abstract}

Keywords: KIT IPA sederhana; penyuluhan; media pembelajaran

\section{Pendahuluan}

Pengajaran IPA yang utuh adalah pengajaran yang mengangkat tiga hakekat IPA, yakni mengembangkan pemahaman para peserta didik tentang alam, mengembangkan keterampilanketerampilan yang diperlukan untuk memperoleh atau mengembangkan pengetahuan yang baru, dan mengembangkan sikap-sikap positif. Untuk mempelajari IPA, yang diimplemetasikan dalam proses belajar-mengajar, guru harus memiliki strategi, agar peserta didik dapat belajar secara efektif dan efisien, mengena pada tujuan yang diharapkan (Roestiyah, 2001). Salah satu langkah untuk memiliki strategi itu ialah harus menguasai teknik-teknik penyajian, atau biasanya disebut metode mengajar.

SMP Islam Bidayatul Hidayah adalah lembaga pendidikan yang berdiri sejak tahun 2018 yang bernaung pada Yayasan Pendidikan Islam Bidayatul Hidayah. YPI BIHA terletak pada wilayah Kecamatan Ampenan Kota Mataram. Berdasarkan hasil wawancara di sekolah tersebut, guru kesulitan dalam menggunakan media pembelajaran pada saat proses pembelajaran. Alasan guru tersebut dikarenakan kurang memadainya media pembelajaran contohnya alat-alat peraga yang dapat digunakan.

Seiring dengan pembaharuan kurikulum dari tahun ke tahun, guru diharapkan dapat mengikuti perubahan-perubahan dalam pembelajaran. Pembelajaran kurikulum 2013 diharapkan membuat siswa aktif, kreatif dan inovatif. Dalam membuat pembelajaran menyenangkan guru dituntut juga kreatif dan menggunakan media pembelajaran yang menarik. Menurut Hamid, et al. (2020), media pembelajaran merupakan sebagai segala sesuatu yang dapat menyampaikan pesan melalui berbagai 
saluran, dapat merangsang pikiran, perasaan, dan kemauan siswa sehigga dapat mendorong terciptanya proses belajar untuk menambah informasi baru pada diri siswa sehingga tujuan pembelajaran dapat tercapai dengan baik. Media pembelajaran membantu guru dalam menyampaikan materi pelajaran. Penggunaan media dalam pembelajaran dapat meningkatkan minat dan motivasi kegiatan belajar mengajar. Guru sebagai fasilitator dalam kegiatan belajar mengajar dituntut agar mampu menggunakan alat-alat yang disediakan sekolah dan dapat mengembangkan bahan ajar dalam bentuk media yang menarik dan interaktif.

Berdasarkan permasalahan di atas, maka perlu adanya suatu usaha agar guru-guru memiliki kemampuan menggunakan alat peraga praktek sederhana sebagai alat bantu untuk mempelajari materi IPA. Alat praktek sederhana tersebut berupa KIT. KIT berarti kotak, sehingga KIT IPA dapat diartikan sebagai kotak yang berisi seperangkat alatalat IPA. Dalam Webster's New Collegiate Dictionary dijelaskan bahwa: Kit is box, bag in which such a Kit is carried yang artinya Kit adalah kotak, tas tempat Kit dan mudah dibawa (Merriem, 1953).

Menurut hasil penelitian menunjukkan bahwa penggunaan alat peraga praktek pada mata pelajaran IPA dapat meningkatkan hasil belajar siswa (Ningsih, R. S., 2011). Memanfaatkan Kit IPA yang sederhana, siswa dapat berhadapan dengan peralatan secara langsung dan melakukan percobaan. Hal ini dapat memberikan manfaat yang cukup besar bagi siswa. Dimana, siswa dapat mencoba, mengalami dan berbuat sesuai dengan kegiatan yang dilakukan oleh ilmuwan ketika bekerja. Untuk membimbing dan mengarahkan siswa untuk melakukan percobaan, sangatlah diperlukan penuntun atau petunjuk yang berisi uraian singkat tentang apa yang harus dilakukan siswa. Melalui pembelajaran ini diharapkan dapat mengubah pola mengajar dari teacher oriented menjadi student oriented, mengembangkan keterampilan proses, mengembangkan sikap ilmiah, serta membangkitkan rasa cinta siswa terhadap alam sekitar. Oleh karena itu, penggunaan KIT sederhana sebagai media pembelajaran efektif di sekolah sangat dibutuhkan dalam pembelajaran IPA

\section{Metode}

Pengabdian ini dilaksanakan dalam bentuk penyuluhan penggunaan KIT IPA sederhana yang dibuat dengan menggunakan bahan yang mudah ditemukan di lingkungan sekitar. Adapun peserta dari penyuluhan ini adalah para guru di SMP YPI Bidayatul Hidayah Ampenan Kota Mataram. Pengabdian ini dilaksanakan dengan tahap yaitu: tahap pertama, penyuluhan cara menggunakan KIT IPA sederhana, dan tahap kedua, membimbing guru menggunakan KIT IPA sederhana.

KIT IPA sederhana yang dibuat, mengacu pada materi IPA dengan topik Tekanan dan Zat.

Pada tahap penyuluhan, tim pengabdian memberikan teori singkat mengenai KIT IPA sederhana. Tim pengabdian mempraktekan cara penggunaan KIT IPA sederhana, diselingi dengan tanya jawab. Tahap selanjutnya tim pengabdian memberikan kesempatan kepada guru-guru untuk mencoba menggunakan KIT IPA sederhana tersebut. Kemudian di akhir sesi, tim pengabdian melakukan evaluasi. Evaluasi ini bertujuan untuk memanfaatkan infromasi yang diperoleh sebagai acuan dalam melakukan perlakuan selanjutnya. Evaluasi ini dilakukan dengan cara meminta guruguru untuk mengungkapkan kesan dan pesan dirasakan setelah mengikuti kegiatan penyuluhan.

Tabel 1. Tahapan dan Metode Kegiatan

\begin{tabular}{llll}
\hline No & Tahapan Kegiatan & Metode Kegiatan \\
\hline 1 & $\begin{array}{l}\text { Desain Rencana } \\
\text { Pelaksanaan }\end{array}$ & $\begin{array}{l}\text { Diskusi dan Tanya } \\
\text { Jawab }\end{array}$ \\
& $\begin{array}{l}\text { Pengabdian Kepada } \\
\text { Masyarakat }\end{array}$ & \\
\hline 2 & $\begin{array}{l}\text { Penyusunan Materi } \\
\text { Pengabdian Kepada } \\
\end{array}$ & Unjuk Kerja & \\
& Masyarakat & & \\
\hline 3 & Koordinasi dengan & Koordinasi dan \\
& Mitra & Komunikasi & \\
\hline 4 & $\begin{array}{l}\text { Penyiapan Sarana } \\
\text { Prasarana }\end{array}$ & Spanduk dan LCD \\
\hline 5 & Penyuluhan & Presentasi & \\
\hline 6 & Penyusunan Laporan & Unjuk Kerja & \\
& dan Luaran & & \\
& Pengabdian & & \\
\hline
\end{tabular}




\section{Hasil dan Pembahasan}

\section{a. Desain Rencana Pelaksanaan Kegiatan}

Pada tahap ini tim pengabdian melakukan penyusunan rencana desain kegiatan. Hasil desain tersebut didiskusikan melalui rapat koordinasi internal tim sehingga menghasilkan rencana yang sistematis, terukur serta dapat dikendalikan. Kegiatan pengabdian yang direncanakan berkaitan dengan penyuluhan penggunaan KIT sederhana sebagai media pembelajaran IPA yang terdiri atas penyusunan desain kegiatan, penyusunan materi penyuluhan, koordinasi dengan mirea, penyiapan sarana dan prasarana, penyuluhan serta penyusunan laporan dan luaran kegiatan. Dalam perencanaan desain tersebut ditentukan pula waktu pelaksanaan, cara melaksanakan, pihak yang terlibat serta tempat pelaksanaan penyuluhan.

\section{b. Penyusunan Materi Pengabdian}

Penyusunan materi pengabdian dilaksnakan diawali dengan melakukan identifikasi tentang cakupan materi yang akan disusun, identifikasi literatur, pembuatan alat peraga yang akan ditampilkan dan materi dalam bentuk power point mengenai KIT IPA sederhana yang telah dibuat.

KIT IPA sederhana yang telah dibuat merupakan implementasi dari salah satu topik IPA yaitu hukum Pascal. Sehingga KIT ini digunakan untuk membuktikan bagaimana hukum Pascal bekerja. Adapun rancangan alat ini dapat dilihat pada gambar berikut.

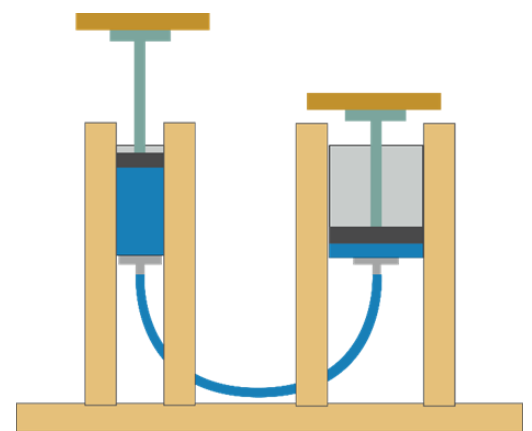

Gambar 1. Rancangan KIT IPA tentang hukum Pascal

Bahan-bahan yang digunakan pada pembuatan KIT tersebut adalah bahan yang mudah ditemukan di lingkungan sekitar seperti, suntikan, selang transparan, kayu dan papan triplek. Tidak lupa pula untuk menyatukan semua bagian menjadi satu dibutuhkan lem tembak yang mudah didaptakan.

Berikut adalah purwarupa dari KIT IPA sederhana yang dibuat berdasarkan rancangan di atas.

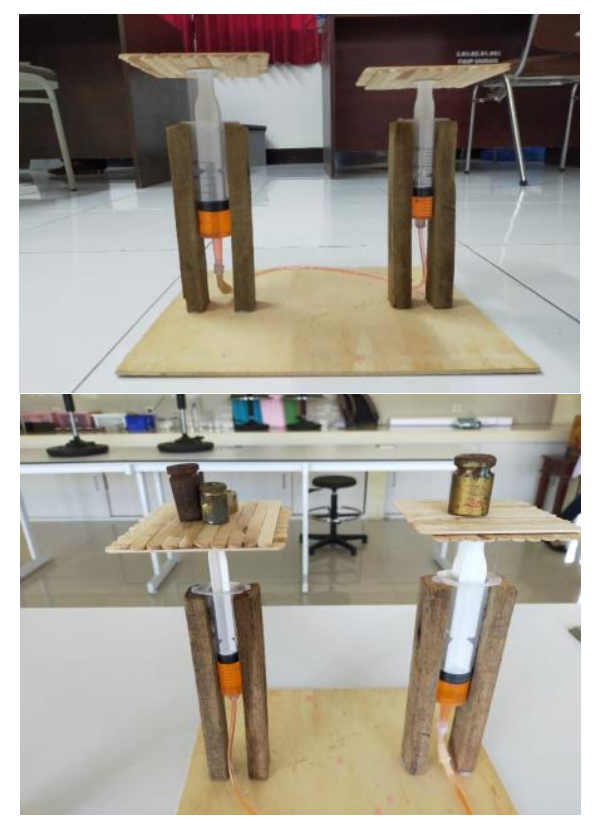

Gambar 2. Purwarupa KIT IPA sederhana

\section{c. Koordinasi dengan Mitra}

Sebelum pengabdian dilakukan terlebih dahulu dilaksanakan mediasi dengan mitra yang terlibat dalam kegiatan ini. Mitra yang dilibatkan dalam kegiatan pengabdian ini adalah SMP Islam YPI Bidayatul Hidayah Ampenan Kota Mataram. Dalam koordinasi tersebut diungkapkan rencana kegiatan, baik nama kegiatan, tujuan kegiatan, sasaran kegiatan, tempat kegiatan, dan cara pelaksanaan kegiatan.

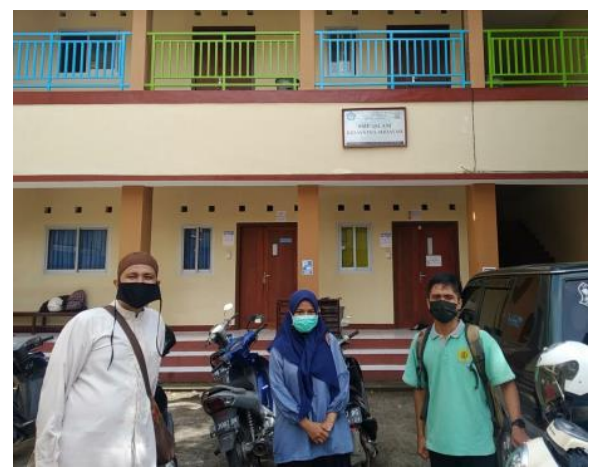

Gambar 3. Observasi sekaligus wawancara dengan kepala sekolah 
Tim pengabdi melakukan wawancara kepada Kepala sekolah SMP Islam YPI Bidayatul Hidayah, dimana dikatakan bahwa di sekolah tersebut tidak tersedianya alat peraga yang dapat dijadikan media pembelajaran pada mata pelajaran IPA. Sehingga dikemukakan kepada mitra bahwa tim pengabdi merencakan akan melaksanakan kegiatan Penyuluhan Penggunaan KIT IPA sederhana Sederhana sebagai Media Pembelajaran Efektif pada Siswa di YPI Bidayatul Hidayah Ampenan. Tujuan dari kegiatan ini adalah (1) Edukasi dan pembelajaran kepada guru SMP Islam Bidayatul Hidayah terkait pemanfaatan barangbarang yang terdapat di sekitar lingkungan untuk dijadikan Kit IPA sederhana; (2) Edukasi dan pembelajaran pembuatan Kit IPA sederhana pada pokok materi tekanan dan zat. Sasaran kegiatan ini adalah guru-guru SMP Islam YPI Bidayatul Hidayah Ampenan dimana peserta yang mengikuti sebanyak 17 orang. Pelaksanaan kegiatan ini bertempat di SMP Islam YPI Bidayatul Hidayah Ampenan Kota Mataram.

\section{d. Penyiapan Sarana dan Prasarana}

Pada tahap ini, kami memastikan saranan dan prasarana telah tersedia sebelum kegiatan penyuluhan ini dilakukan. Adapun sarana dan prasarana yang dimaksud adalah laptop, LCD proyektor, spanduk, kamera untuk dokumentasi, konsumsi peserta serta lokasi yang memadai untuk dilakukan kegiatan. Selain itu, peserta harus diatur agar posisi duduknya tidak berdekatan satu sama lain sehingga mengikuti protokol kesehatan yang berlaku. Penggunaan masker pada saat kegiatan kami lakukan agar protokol kesahatan tetap dijaga.

\section{e. Penyuluhan}

Penyuluhan dengan topik Penggunaan KIT IPA sederhana Sederhana sebagai Media Pembelajaran Efektif pada Siswa di YPI Bidayatul Hidayah Ampenan disampaikan sesuai dengan rencana materi yang telah didesain pada tahap penyusunan materi penyuluhan. Namun, pada pelaksanaan penyuluhan tim pengabdian tidak bisa menampilkan materi tersebut dikarenakan tidak tersedianya LCD, sehingg pemateri hanya menyampaikan tanpa menampilkan materi yang ada pada power point yang telah disusun.

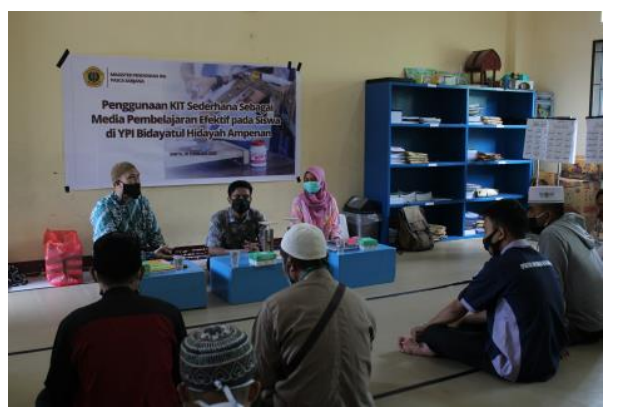

Gambar 4. Pelaksanaan Kegiatan Penyuluhan

Pada tahap pelaksanaan penyuluhan tim pengabdi melakukan tahap evaluasi untuk mendengan respon dari guru di SMP Islam Bidayatul Hidayah. Evaluasi tersebut dengan cara meminta peserta mengungkapkan kesan dan pesan yang dirasakan selama mengikuti kegiatan penyuluhan ini. Berdasarkan hasil evaluasi tersebut, peserta merasa sangat antusias dalam mengikuti kegiatan penyuluhan ini. Peserta mendapatkan edukasi bahwa pembuatan media pembelajaran dapat memanfaatkan barang-barang di sekitar lingkungan tempat tinggal.

Pada sesi terakhir dari kegiatan penyuluhan dilakukan penyerahan KIT IPA sederhana kepada Kepala Sekolah di SMP Islam Bidayatul Hidayah Ampenan sebagai media yang dapat digunakan dalam proses pembelajaran IPA.

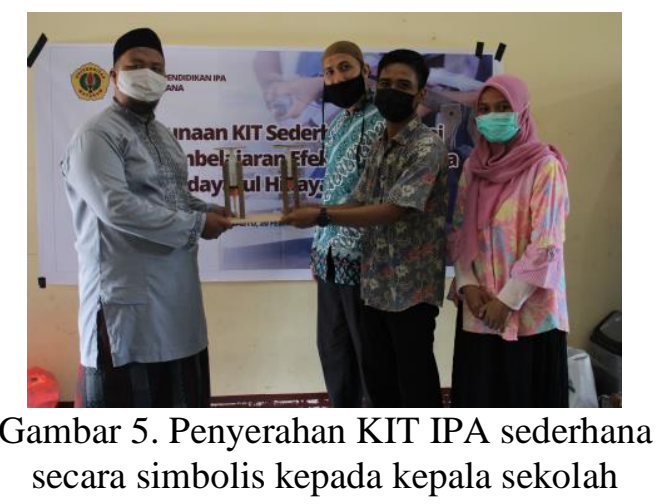

\section{f. Penyusunan Laporan dan Luaran}

Tahap akhir dari kegiatan pengabdian ini adalah penyusunan laporan. Penyusunan laporan pengabdian disusun berdasarkan sistematika format yang telah ditetapkan. Selain itu, telah 
disusun luaran kegiatan, yang telah disubmit pada Jurnal Pengabdian Magister Pendidikan IPA Universitas Mataram.

\section{Kesimpulan}

Kegiatan pengabdian ini berjalan dengan lancar tanpa mengalami kendala yang berarti. Harapan dari kegiatan ini adalah para guru IPA tergugah untuk membuat media pembelajaran yang sederhana namun relevan dengan topik IPA yang diajarkan. Media pembelajaran tidak hanya KIT IPA laboratorium yang lengkap, akan tetapi dapat dibuat dengan bahan-bahan yang mudah ditemukan di lingkungan sekitar. Dengan begitu, para guru tidak perlu menunggu tersedianya KIT IPA terlebih dahulu untuk mengajarkan topik IPA.

Harapan untuk kegiatan pengabdian selanjutnya, KIT IPA sederhana yang dibuat dapat lebih beragam untuk beberapa topik IPA yang ada di SMP.

\section{Ucapan Terima Kasih}

Penulis mengucapkan terima kasih kepada Dosen Pengampu mata kuliah studi mandiri Dr. Drs Abdul Syukur, M.Si dan Dr. Jamaluddin, M.Pd.

\section{Daftar Pustaka}

Hamid, A. Mustofa., Ramadhani, Juliana, Safitri, Mumsarif, Simarmata. (2020). Media Pembelajaran. Jakarta: Yayasan Kita Menulis.

Roestiyah. (2001). Strategi Belajar Mengajar, Rineka Cipta : Jakarta.

Merriem Webster. (1953). Webster's Dictionary. Miamy Florida: PSI and Ass Inc.

Ningsih, Rachma Suprapti. (2011). Problematika Pembelajaran IPA Kelas V Materi Peredaran Darah Manusia di Sekolah Dasar Gugus III Kecamatan Pakisaji Kabupaten Malang, Skripsi. Program Studi PGSD FIP, Universitas Negeri Malang : Malang. 